\title{
Membrane targeting peptides toward antileishmanial activity: Design, structural determination and mechanism of interaction
}

\author{
Danubia Batista Martins ${ }^{\mathrm{a}}$, Maira Ramos Vieira ${ }^{\mathrm{b}}$, Valmir Fadel ${ }^{\mathrm{a}}$, \\ Viviane Aparecida Camargo Santana ${ }^{\mathrm{b}}$, Mirian Elisa Rodrigues Guerra ${ }^{\mathrm{a}}$, Marta Lopes Lima ${ }^{\mathrm{c}, \mathrm{d}}$, \\ Andre G. Tempone ${ }^{\mathrm{d}}$, Marcia Perez dos Santos Cabrera ${ }^{\mathrm{a}, \mathrm{b}, *}$ \\ a Departamento de Física, Universidade Estadual Paulista, São José do Rio Preto, SP, Brazil \\ b Departamento de Química e Ciências Ambientais, Universidade Estadual Paulista, São José do Rio Preto, SP, Brazil \\ ${ }^{\mathrm{c}}$ Instituto de Medicina Tropical, Universidade de São Paulo, São Paulo, SP, Brazil \\ ${ }^{\mathrm{d}}$ Centre for Parasitology and Mycology, Instituto Adolfo Lutz, São Paulo, SP, Brazil
}

\section{A R T I C L E I N F O}

\section{Keywords:}

Decoralin

Antimicrobial peptides

Peptide-lipid bilayer interactions

NMR

Molecular dynamics simulations

Aminophospholipids

\begin{abstract}
A B S T R A C T
Background: Leishmaniasis threatens poor areas population worldwide, requiring new drugs less prone to resistance development. Antimicrobial peptides with antileishmanial activity are considered among fulfilling alternatives, but not much is known about the mode of action of membrane-targeting peptides, considering promastigote and infected macrophage membranes. In a previous work, structural features of very active known peptides were prospected using molecular dynamics simulations.

Methods: Combining sequences of these peptides, analogs were designed. The structure of analog DecP-11 was validated by NMR. In vitro bioassays determined the peptide cytotoxicity toward mammalian cells, $\mathrm{IC}_{50}$ values on promastigotes and amastigotes, and membranolytic activity compared to Decoralin, one of the parent peptides. With biophysical methods, the mechanism of interaction with membrane mimetic systems was investigated. Results: The designed peptide exhibits potent cytolytic and membrane permeabilizing activities, and decreased antileishmanial activity compared to the parent peptide. Interactions with lipid bilayers mimicking those of promastigotes, infected macrophage and mammalian cells showed that these peptides strongly bind to vesicles with intense lytic activity at low concentrations. Additionally, circular dichroism and light scattering experiments showed changes in the secondary structure of peptides and in vesicle size, depending on vesicles compositions. Altogether they suggest that DecP-11 antileishmanial activity is impaired by the aggregation and that aminophospholipids are probably involved.

Conclusions: DecP-11 potent cytolytic and membranolytic activities with lack of selectivity toward promastigote model membranes warrant further structural studies to improve selectivity.

General significance: Strong interactions of peptides with aminophospholipids, abundant in parasite membranes, potentially lead to aggregated forms impairing activity.
\end{abstract}

\section{Introduction}

Bioactive peptides are known for their structural features as low molecular weight, cationicity and amphipathicity, which have been extensively correlated to their antimicrobial, tumoricidal and hemolytic activities [1,2]. Despite their different sources and sequences, they usually share a common target, the phospholipid matrix of the cell membrane $[2,3]$. This represents an advantage because membrane compositions were conserved throughout evolution [2,4]. As a consequence, mechanisms of resistance are harder to develop and justify the efforts driven in the search for alternative antibiotics and anticancer compounds with improved selectivity. Many of these peptides also exhibit antileishmanial activity [5-11] and similarly, their mode of action involves, among others, alterations of the plasma membrane permeability (including pore-forming activity), which leads to cell death $[5,6]$.

The main lipids in eukaryotic cell membranes are the zwitterionic phospholipids phosphatidylcholine (PC), its analog, sphingomyelin (SPM), and phosphatidylethanolamine (PE) and the sterol, cholesterol (Chol). At physiologic pH and healthy conditions, PC, SPM, and Chol prevail at the outer leaflet of the membranes [2], while PE and ca. 10\% phosphatidylserine (PS) are found in the inner leaflet [12-14]. The lipid

\footnotetext{
* Corresponding author at: Departamento de Química e Ciências Ambientais, Universidade Estadual Paulista, São José do Rio Preto, SP, Brazil.

E-mail address: cabrera.marcia@gmail.com (M.P. dos Santos Cabrera).
} 
composition of Leishmania membranes differs from those of eukaryotes $[5,6]$. This difference is the basis of the action of drugs like miltefosine, an analog to lysophospholipids, in clinical use for visceral leismaniasis $[15,16]$. The plasmatic membrane of the extracellular promastigote form of Leishmania is densely covered by an anionic polysaccharide, the lipophosphoglycan, which is responsible for the net negative charge of its surface. Instead, the intracellular amastigote form exhibits mostly glycoinositolphospholipids and anionic phospholipids that also ascribe a negative surface charge to their membranes [6], and promote a preferential interaction with cationic antimicrobial peptides [10]. Additionally, Leishmania membranes contain a mixture of sterols, predominantly ergosterol [17] instead of cholesterol found in eukaryotic membranes [6]. Infected or non-infected macrophage membranes also differ in relation to their lipid composition [18]. While basic knowledge about antimicrobial peptides structure-function relationships and their interactions with membranes is rapidly accumulating, much less is known on how the subtle differences among lipid bilayers influence the efficiency of cationic peptides [19].

Among antimicrobial peptides from wasp venoms, the undecapeptide Decoralin (PDB ID: 2N9A), in its amidate form [20], and the tetradecapeptide EMP-ER [21] showed antileishmanial activity on promastigotes, with $\mathrm{IC}_{50}$ values of 11 and $20 \mu \mathrm{M}$, respectively. Widely known as antileishmanials are the antimicrobial peptides found in amphibian secretions as Phylloseptin-1 (19 residues) [11], Bombinin H4 (20 residues) [22,23] and Temporins A and B (13 residues) [24,25], which present $\mathrm{IC}_{50}$ values of $0.5,1.7$ and $8.5 \mu \mathrm{M}$, respectively. Previous studies demonstrated that these peptides target the lipid membrane and assume a helical conformation in the presence of membrane mimetics. These observations and the need for alternative drugs targeting one of the world's neglected diseases $[6,7]$ lead us to focus on the search for peptides of shorter chain length through an optimized study of structure-function relationships.

In the present work, we used molecular dynamics simulations (MD) of peptides with known antileishmanial activity, Phylloseptin-1 (PH-1), Temporin B (TB) and amidated Decoralin (DCN), to search for their ubiquitous and remarkable structural characteristics and then, to design a new peptide whose structural features could match those of the reference peptides (Table 1). To verify if this objective was achieved, the designed peptide, DecP-11, was submitted to a NMR structure determination in $30 \%$ trifluoroethanol (TFE) solution, which is considered an environment that mimics the anisotropic character of lipid bilayers [26]. Then, this peptide was assayed for cytotoxicity (toward NCTC cells) and antileishmanial activity in vitro (toward promastigotes and amastigotes) in comparison to DCN, to a cyclic DCN analog and miltefosine. The results obtained in the bioassays lead to the investigation of peptides interactions with vesicles, whose lipid compositions approximately mimic those of promastigotes [22,27] infected macrophages [18] and mammalian erythrocytes $[28,29]$. We found that peptides strongly bind to vesicles and their lytic activity is intense at low concentrations. Combining circular dichroism (CD) and dynamic light scattering (DLS) results, that means, changes in the secondary structure of peptides and in vesicle size observed at the different vesicle compositions, suggest that the antileishmanial activity of DecP-11 is impaired by aggregation and that aminophospholipids are probably involved.

Table 1

Sequences of the antileishmanial peptides used as references and the designed DecP-11, with the respective net charge $(\mathrm{z})$, mean hydrophobicity values $(<\mathrm{H}>)$ and hydrophobic moment, calculated according to Eisenberg et al., 1984 [30]. Positively charged residues in bold.

\begin{tabular}{llccc}
\hline & & $z$ & $<H>$ & $\mu$ \\
\hline DCN [20] & SLLSLIRKLIT $_{\text {NH2 }}$ & +3 & 0.028 & 0.403 \\
TB [24] & LLPIVGNLLKSLL $_{\text {NH2 }}$ & +2 & 0.195 & 0.307 \\
PH-1 [11] & FLSLIPHAINAVSAIAKHN $_{\text {NH2 }}$ & +3 & 0.085 & 0.240 \\
DecP-11 & SWLSLIRKLINSLL $_{\text {NH2 }}$ & +3 & 0.014 & 0.371 \\
\hline
\end{tabular}

\section{Methods}

\subsection{Design of DecP-11}

Molecular dynamics simulations were carried out in 30\% 2,2,2-trifluoroethanol solution as described in SI (2.1.1) and summarized in Table SI1, for the peptides PH-1, TB and DCN. The characteristics of their secondary structure profile were analyzed in relation to parameters that were considered important for antimicrobial activity as length and stability of the helical stretch and amphipathicity $[1,31]$. Then, modifications to the DCN sequence were made and simulations were performed until the sequence of DecP-11 was obtained, matching the structural parameters found for $\mathrm{PH}-1$, the most active peptide.

\subsection{Peptide synthesis, purification and mass spectrometry analyses}

Peptides were supplied by GenScript (Piscataway, NJ). Mass spectrometry analyses showed MW according to expected and purity above $97 \%$ for linear peptides and $80 \%$ for the cyclic Decoralin. Concentration of peptides in the experiments was corrected according to their respective data on purity.

\subsection{Bioassays}

\subsubsection{Reagents}

3-[4,5-Dimethylthiazol-2-yl]-2,5-diphenyltetrazolium bromide (MTT; thiazol blue), M-199 medium, RPMI-PR - 1640 medium (without phenol red), Hank's balanced salts and others were obtained from Sigma (Brazil). Dimethyl sulfoxide (DMSO) was obtained from Merck (Brazil). SYTOX Green was purchased from Molecular Probes (Invitrogen, Brazil).

\subsubsection{Parasites, mammalian cells, and animal maintenance}

Leishmania (L.) infantum (MHOM/BR/1972/LD) promastigotes were cultured in M-199 medium supplemented with $10 \%$ fetal bovine serum (FBS) and $0.25 \%$ hemin at $24{ }^{\circ} \mathrm{C}$. Intracellular amastigotes forms were obtained from the spleens of previously infected golden hamsters (Mesocricetus auratus) by differential centrifugation. The macrophages were collected from the peritoneal cavity of BALB/c mice by washing with RPMI-1640 (without phenol red and supplemented with $10 \%$ FBS). NCTC (clone L-929) murine conjunctive cells were maintained in RPMI-1640 (without phenol red and supplemented with 10\% FBS) at $37{ }^{\circ} \mathrm{C}$ in a humidified atmosphere containing $5 \% \mathrm{CO}_{2}$. BALB/c mice and Golden hamsters were maintained as described elsewhere [33]. Animal procedures were performed with the approval of Research Ethics Commission (CEUA IAL 02/2011) in agreement with the Guide for the Care and Use of Laboratory Animals from the National Academy of Sciences.

\subsubsection{Activity of the peptides on leishmania promastigotes}

DCN, DecP-11 and cDec peptides were dissolved in DMSO and tested to the highest concentration of $100 \mu \mathrm{M}$ in M-199 medium, supplemented with $10 \%$ FBS. Briefly, promastigotes were seeded at $1 \times 10^{6}$ cells/well in 96-well microplates and incubated with peptides for $48 \mathrm{~h}$ at $24^{\circ} \mathrm{C}$. Miltefosine was used as a standard drug. Promastigotes viability was determined using the colorimetric MTT assay as previously described [33].

\subsubsection{Activity of the peptides on leishmania amastigotes}

Briefly, $1 \times 10^{5}$ peritoneal macrophages/well were infected with Leishmania (L.)-infantum amastigotes at 1:10 ratio (macrophage/amastigotes) for $24 \mathrm{~h}$ at $37^{\circ} \mathrm{C}, 5 \% \mathrm{CO}_{2}$. Infected macrophages were incubated with the peptides for $120 \mathrm{~h}$ at $37{ }^{\circ} \mathrm{C}$ in $5 \% \mathrm{CO}_{2}$. Miltefosine was used as standard drug. Finally, cells were fixed in methanol, stained with Giemsa and 200 macrophages per concentration tested and control were counted under a light microscope [33]. 


\subsubsection{Cytotoxicity against mammalian cells}

NCTC clone L-929 cells were seeded at $6 \times 10^{4}$ cells/well in 96-well microplates and incubated with peptides for $48 \mathrm{~h}$ (maximal concentration of $200 \mu \mathrm{M}$ ) at $37{ }^{\circ} \mathrm{C}$ in a $5 \% \mathrm{CO}_{2}$. The viability of the cells was also determined by MTT assay at $570 \mathrm{~nm}$ [33].

\subsubsection{Plasma membrane permeabilization assays in L. (L.) infantum promastigotes}

The Sytox Green assay was performed to detect membrane alterations in the permeability of the promastigotes plasma membrane [34]. Briefly, promastigotes were harvested at late exponential growth phase, seeded at $2 \times 10^{6} /$ well in Hank's medium supplemented $10 \mathrm{mM}$ glucose and incubated with $1 \mu \mathrm{M}$ SYTOX Green for $15 \mathrm{~min}$ in the dark. Then, peptides were added at the $\mathrm{IC}_{90}$ value and the fluorescence intensity was measured during $1 \mathrm{~h}$ incubation, using the FilterMax F5Multi-Mode Microplate Reader (Molecular Devices) with excitation and emission wavelength set at 485 and $520 \mathrm{~nm}$, respectively. Maximum permeabilization was obtained with $0.1 \%$ Triton X-100. Internal controls consisted of untreated promastigotes and medium without any cells as negative control and blank, respectively [34].

\subsubsection{Statistical analysis}

The $50 \%$ inhibitory concentration ( $\mathrm{IC}_{50}$ ) against both forms of Leishmania (L.) infantum and the $50 \%$ cytotoxic concentration $\left(\mathrm{CC}_{50}\right)$ against NCTC cells were calculated using sigmoid dose-response curves in Graph Pad Prism 5.0 software (GraphPad Software, San Diego, CA, USA). The $95 \%$ confidence intervals of one representative assay are also reported (in parentheses). At least two independent assays were performed for each activity tested. The differences were statistically defined by the two-tailed unpaired Students $t$-test, and an ANOVA test was used to test its significance $(P<0.05)$.

\subsection{Assays in mimetic membranes}

\subsubsection{Reagents}

Avanti Polar Lipids (Alabaster, AL) supplied the phospholipids egg sphingomyelin (eSPM), 1-palmitoyl-2-oleoyl-sn-glycero-3-phosphocholine (PC), 1-palmitoyl-2-oleoyl-sn-glycero-3-phospho-(1'-rac-glycerol) sodium salt (PG), and 1-palmitoyl-2-oleoyl-sn-glycero-3-phospho-Lserine, sodium salt, (PS). Sigma-Aldrich Co. (S. Louis, MO) supplied egg L- $\alpha$-lysophosphatidylcholine (L), cholesterol (Chol), ergosterol (Erg), and 5,6-carboxyfluorescein (CF). All materials were used as supplied. Other chemicals were of high quality analytical grade.

\subsubsection{Large unilamellar vesicle (LUV) preparations}

Films were made according to the procedures previously described (Dos Santos Cabrera et al., 2014) [35] at the following lipid compositions: PC/PS 82:18, 63:37 and 50:50; PE/PS 50:50 and 72:28; PC/PG 50:50; PEPSErg 47:28:25 (mimicking the membrane of the promastigote) [22]; PCPEPSL 39:29:18:14 (mimicking the membrane of the infected macrophage) [18], and 40:36:24 PC/eSPM/Chol (mimicking an average red blood cell) $[28,29]$. Then, they were hydrated with appropriate buffers (10 mM HEPES, containing $150 \mathrm{mM} \mathrm{NaF}$, pH 7.4 for the zeta potential experiments or $10 \mathrm{mM}$ TRIS/ $\mathrm{HCl}$, with $1 \mathrm{mM}$ $\mathrm{Na}_{2}$ EDTA and $25 \mathrm{mM} \mathrm{CF}$, pH 7.4 for the CF-filled LUVs) at room temperature or at $40{ }^{\circ} \mathrm{C}$ when cholesterol or ergosterol was present, to give lipid concentration around $10 \mathrm{mM}$. LUVs with a mean diameter of $125-130 \mathrm{~nm}$ were obtained after extrusion.

\subsubsection{Zeta potential determination and size measurements}

The binding of peptides was assessed through the changes in zeta potential of the anionic LUVs with a Zetasizer Nano ZS (Malvern Instruments, Worcestershire, U.K.). Aliquots of vesicle suspension to give a final concentration of 50 or $33.3 \mu \mathrm{M}$ (for peptides with +3 or
+2 net charge, respectively) were added to buffered peptide solutions, $\mathrm{pH} 7.4$, in $1.5 \mathrm{~mL}$ plastic vials. Each preparation was equilibrated for $30 \mathrm{~min}$ at $25{ }^{\circ} \mathrm{C}$. Next, each preparation was transferred to a disposable cuvette for size evaluation and, afterwards, to a DTS1070 cell (Malvern Instruments) for zeta potential measurement, considering water viscosity and refraction index of $0.8872 \mathrm{cP}$ and 1.330 , respectively [36]. Quantifying peptide partition from the aqueous media to lipid bilayers reports the extension of the interaction. This was carried out according to the method proposed by Freire et al. (2011) [36]: $\frac{\zeta_{\text {final }}}{\zeta_{0}}=1+\frac{X_{L z_{p e p}}}{f_{P L}[L] z_{\text {lip }}} .[P]$ where $z_{\text {pep }}$ and $z_{\text {lip }}$ are the net charges of peptide and lipids, respectively; $\zeta_{\text {final }}$ and $\zeta_{0}$ are the zeta potential values obtained, respectively, at each peptide concentration and in the absence of peptide; $X_{L}$ is the molar fraction of bound peptide; [L] and [P] the lipid and peptide concentrations, respectively; and $f_{P L}$ the fraction of anionic phospholipids in the vesicles. From this relation $X_{L}$ is determined and partition constant $\left(K_{P}\right)$ can be calculated from $X_{L}=\frac{K_{P} \gamma_{L}[L]}{1+K_{P} \gamma_{L}[L]}[37]$.

\subsubsection{Dye leakage}

$\mathrm{CF}$ leakage experiments were performed using the Perkin Elmer LS45 spectrofluorometer (Perkin Elmer, Beaconsfield, UK), at $25^{\circ} \mathrm{C}$, with LUVs as previously described [35]. The percentage of CF release was calculated using the following equation: \% leakage $=100 \times(\mathrm{F}$ $\left.\mathrm{F}_{0}\right) /\left(\mathrm{F}_{100}-\mathrm{F}_{0}\right)$, where $\mathrm{F}$ is the observed fluorescence intensity, $\mathrm{F}_{0}$ and $\mathrm{F}_{100}$ correspond, respectively, to the fluorescence intensities in the absence of peptides and to $100 \%$ leakage, as determined by the addition of $20 \mu \mathrm{l}$ of $10 \%$ Triton X-100 solution. $\mathrm{F}_{100}$ has been corrected for the corresponding dilution factor.

\subsubsection{Circular dichroism (CD) measurements}

CD spectra were acquired for $20 \mu \mathrm{M}$ peptide in buffer, in 40\% TFE and $8 \mathrm{mM}$ SDS solution and in the presence of 100, 200 and $300 \mu \mathrm{M}$ LUV suspension in the different lipid compositions. Spectra were recorded from 260 to $200 \mathrm{~nm}$ with a Jasco-815 spectropolarimeter (JASCO International Co. Ltd., Tokyo, Japan), at $25{ }^{\circ} \mathrm{C}$, using a $0.5 \mathrm{~cm}$ cell path length, averaged over eight scans, at a scan speed of $50 \mathrm{~nm} /$ min, bandwidth of $1.0 \mathrm{~nm}, 0.5 \mathrm{~s}$ response and $0.1 \mathrm{~nm}$ resolution. Following baseline correction, the observed ellipticity ( $\theta$ (mdeg)) was converted to mean residue ellipticity $\left([\Theta]\left(\mathrm{deg} \mathrm{cm}^{2} / \mathrm{dmol}\right)\right.$ ) using the relationship $[\Theta]=100 \theta /(1 \mathrm{c} \mathrm{n})$, where 1 is the path length in centimeters, $\mathrm{c}$ is peptide millimolar concentration, and $\mathrm{n}$ the number of peptide bonds. Contents of secondary structure elements were estimated by CDSSTR program on the DICHROWEB online server.

\subsubsection{NMR spectroscopy and molecular modeling}

The lyophilized peptide was dissolved in $550 \mu \mathrm{l}$ of a $30 \%$ trifluoroethanol (TFE) perdeuterated aqueous solution $\left(5 \% \mathrm{D}_{2} \mathrm{O}\right)$ to yield a concentration of $2.1 \mathrm{mM}$. After solubilization, small amounts of $\mathrm{HCl}$ solution was added until $\mathrm{pH}=5.1$. All two-dimensional ${ }^{1} \mathrm{H}-\mathrm{NMR}$ experiments were carried out on a Varian Unity 600 spectrometer operating at $599.887 \mathrm{MHz}$ for ${ }^{1} \mathrm{H}$ frequency, at $298 \mathrm{~K}$. The proton chemical shifts were referenced to 4,4-dimethyl-4-silapentane-1-sulfonate, DSS $(0.00 \mathrm{ppm})$. All two-dimensional experiments were acquired in the phase-sensitive mode using the States method. The spectra width was typically $6.6 \mathrm{kHz}$. Detailed information on spectra analysis and molecular modeling are supplied as SI [38-42].

\section{Results}

\subsection{Design of DecP-11}

As described in SI, molecular dynamics simulations of peptides PH1 , TB and DCN indicated the predominance of the $\alpha$-helical pattern (Figure SI1) with significant differences among them in the stability and 


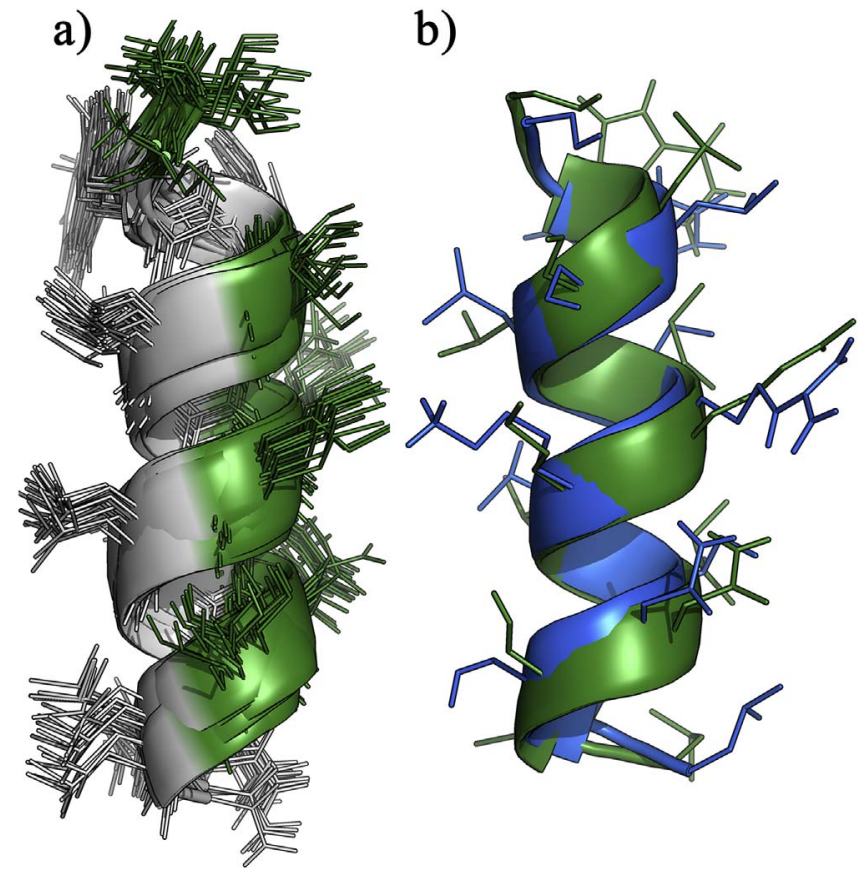

Fig. 1. NMR and MD structures of DecP-11. a) Superposition of final 20 calculated structures of the peptide in $30 \%$ TFE at $298 \mathrm{~K}, \mathrm{pH} 5.1$, displaying the backbone and the hydrophobic amino acids in gray and the polar in green. b) Overlay of a representative structure obtained from NMR (in green) and that obtained in MD experiments (in blue). The C-terminals are shown at the bottom.

length of the helical stretch (Table SI2). Considering the features of the peptide exhibiting the lowest inhibitory concentration $\left(\mathrm{IC}_{50}\right)$ in the antileishmanial activity on promastigotes [11], $\mathrm{PH}-1$, and those of DCN, which exhibited a closer structure (Figure SI2a), small sequence modifications were made to DCN, considering also the features of TB. Then, simulations were successively performed until DecP-11 was obtained.

Cyclic peptides have been considered more active than their linear counterparts and could help to understand influences of the secondary structure [43]. Thus, we simulated and tested a cyclic Decoralin (cDec), whose features are included in Table SI2 and Figure SI1. As a consequence of losing the amidation of the C-terminal, c-Dec has a lower charge than DCN and does not exhibit an amphipathic structure (Figure SI1).

\subsection{NMR spectroscopy}

The structure of DecP-11 was experimentally determined in $30 \%$ TFE solution to verify if the designed characteristics could be obtained. Sequential resonance assignments were performed based on the combined use of two-dimensional TOCSY and NOESY. Table SI3 displays the ${ }^{1} \mathrm{H}$-NMR chemical shifts. For the molecular modeling, 209 distance constraints containing 64 medium range constraints were collected and taken into account for structure calculation using UNIO. Along this refinement the Target Function evolved from 18.92 $\pm 0.04 \AA^{2}$ to $2.12 \pm 0.34 \AA^{2}$ and the backbone RMSD from $0.26 \pm 0.18 \AA$ with no NOE violation $>0.2 \AA$. The 20 structures were energy minimized using the Gromacs program to reach $10.0 \mathrm{~kJ} / \mathrm{mol}$. After minimization, the bundle of structures was used to represent the solution three-dimensional structure of DecP- 11 in 30\% TFE at $298 \mathrm{~K}$ and $\mathrm{pH}$ 5.1. It shows an average content of $77.5 \%$ of $\alpha$-helix configurations and the set of most frequent structures (12/20) exhibit 11 residues (79\%) in this configuration. Table SI4 shows the statistics of the structure calculation and Ramachandran statistics for the final structures showing $100 \%$ of $\varphi$ and $\psi$ angles in the most favored region. These experimental data were deposited at BMRB under ID 27060. Also, comparing the RMSD values of the representative bundle of DecP-11 structures, (Table SI4, $0.26 \AA$ for the backbone and $0.57 \AA$ for all heavy atoms), with those obtained for the peptide DCN, $(0.33 \AA$ e $0.69 \AA$ respectively [32], indicate that the designed peptide presents less flexibility than its parent analog.

The amphipathic property of DecP-11 can be seen by the colored structure with the K, R, S and $\mathrm{N}$ in green, at one side of the peptide and $\mathrm{I}, \mathrm{L}$ and $\mathrm{W}$, in grey, at the other side, as displayed in the superposition of the 20 final models of DecP-11 (Fig. 1). We also compared the NMR bundle of 20 structures with a representative MD structure, which showed good agreement. The average RMSD value between them is $0.98 \AA$ for the backbone and $2.41 \AA$ for all atoms, considering backbone fitting. Table SI 2 also shows a good agreement between simulated structures and those experimentally obtained.

\subsection{Antileishmanial activity and cytotoxicity of peptides}

The antileishmanial activity of DCN, its analog c-Dec and DecP-11 was assayed in promastigotes and intra-macrophage amastigotes (Table 2). DCN and DecP-11 showed IC $_{50}$ values of 76 and $114 \mu \mathrm{M}$ against $L$. infantum promastigotes, and $\mathrm{CC}_{50}$ value of 62 and $18 \mu \mathrm{M}$ against NCTC mammalian cells, respectively. Miltefosine was used as a standard drug and resulted in $\mathrm{IC}_{50}$ value of $16 \mu \mathrm{M}$ against promastigotes and intracellular amastigotes, with $\mathrm{CC}_{50}$ value of $241 \mu \mathrm{M}$. The peptides DCN and DecP-11 are non-selective as they showed no activity against the intracellular amastigotes and toxicity against the macrophages. The c-Dec analog was completely devoid of activity toward these cells and no toxicity was observed to macrophages.

Table 2

Biological activity of DCN, DecP-11 and c-Dec peptides.

\begin{tabular}{llll}
\hline Compound & $\begin{array}{l}\text { L.(L.) infantum } \\
\text { promastigotes }\end{array}$ & $\begin{array}{l}\text { L. (L.) infantum } \\
\text { amastigotes }\end{array}$ & NCTC \\
\hline & $\mathrm{IC}_{50}{ }^{\mathrm{a}}(\mu \mathrm{M})$ & $\mathrm{IC}_{50}{ }^{\mathrm{a}}(\mu \mathrm{M})$ & $\mathrm{CC}_{50}{ }^{\mathrm{b}}(\mu \mathrm{M})$ \\
& $\mathrm{CI} 95 \%$ & $\mathrm{CI} 95 \%$ & $\mathrm{CI}^{2} \%$ \\
DCN & 76.2 & $\mathrm{NS}$ & 62.4 \\
& $(67.33-86.20)$ & $\mathrm{NS}$ & $(39.75-98.09)$ \\
DecP-11 & 114.7 & & 18.0 \\
& $(100.3-131.1)$ & $\mathrm{NA}$ & $(13.87-23.56)$ \\
c-Dec & $\mathrm{NA}$ & 16.4 & $>200$ \\
Miltefosine & 16.7 & $(15.45-17.46)$ & $(206.9-281.6)$ \\
& $(13.07-21.52)$ & & \\
\hline
\end{tabular}

CI95\%: 95\% confidence interval. NA: Not active $\left(\mathrm{IC}_{50}>100 \mu \mathrm{M}\right)$; NS: Not selective.

${ }^{\mathrm{a}} \mathrm{IC}_{50}: 50 \%$ inhibitory concentration.

${ }^{\mathrm{b}} \mathrm{CC}_{50}: 50 \%$ Cytotoxicity concentration.

\subsubsection{Plasma membrane permeabilization assays in $L$. (L.) infantum promastigotes}

The permeabilizing activity of peptides DCN and DecP-11 was assessed by the measurement of the fluorescence of the Sytox Green dye. The entrance of this dye requires severe damage to the plasma membrane due to its relatively high molecular weight $(\mathrm{Mw}=600 \mathrm{Da})$. Once it achieves the cytoplasm, it binds exclusively to the nucleic acids enhancing its fluorescence. For both peptides, the rapid influx of Sytox Green, leading to increased fluorescence, could be measured immediately after the addition of peptides. At $90 \%$ inhibitory concentration, $\mathrm{IC}_{90}$, the fluorescence intensity of DecP-11 was comparable to that achieved in promastigotes, when they were completely permeabilized by the treatment with a $0.1 \%$ Triton X-100 detergent solution. In contrast, DCN increased the fluorescence at a lower rate, reaching $64 \%$ of the maximum intensity of the control (Fig. 2).

\subsection{Assays in mimetic membranes}

Aiming to improve our designing technique based on MD simulations, to obtain a deeper insight into the structure-function 


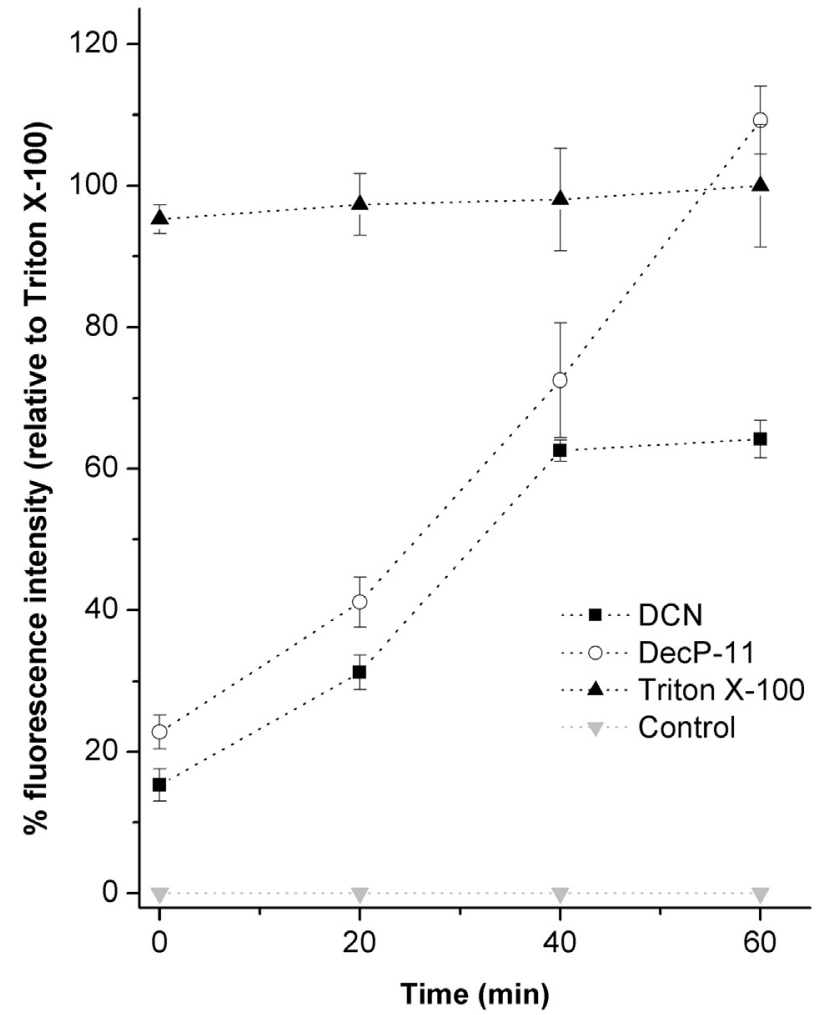

Fig. 2. DCN and DecP-11 $(200 \mu \mathrm{M})$ plasma membrane permeabilization of $L$. infantum promastigotes. The entrance of Sytox Green dye was monitored by the increase of its fluorescence (Ex. $485 \mathrm{~nm}, \mathrm{Em} .520 \mathrm{~nm}$ ) during $1 \mathrm{~h}$ incubation with the peptides. Triton X100 was used to achieve maximum permeabilization.

relationships of the designed peptides in comparison to the synthetic DCN, and to search for the reason of the lack of selectivity of DecP-11, experiments with lipid vesicles mimicking the membranes of the promastigote, of the infected macrophage and of erythrocytes were carried out. Since these mimetic systems are composed by three or four different phospholipids, a set of simpler LUVs made of two phospholipids was also used to study their influence on the binding of the peptides.

\subsubsection{Zeta potential and size measurements}

To quantify the interaction of peptides with lipid bilayers, zeta potential measurements were performed and using the mathematical model proposed by Freire et al. (2011) [36] the lipid/water partition constants $\left(K_{p}\right)$ were calculated. Fig. 3 depicts the adsorption isotherms of peptides to PEPSErg vesicles, considering the peptide concentration range in which no signs of vesicles aggregation where observed. DecP-11 exhibits the more efficient charge neutralization, especially on infected macrophage mimetic membrane. DCN did not reach charge neutralization in the promastigote mimetic membrane and c-Dec shows the lowest binding. Fig. 4 compares the $K_{p}$ values determined for the anionic bilayers.

Considering that DCN and DecP-11 have the same net charge and a relatively small difference in relation to their mean hydrophobicity, we investigated the influence of the anionic character of the bilayers by determining $K_{p}$ values in the presence of increasing concentrations of PS and by substituting PS by PG. The increase in PS content showed poor effect on the peptides' binding to these vesicles. Changing the anionic phospholipid to PG significantly increased the binding of DCN, but not the binding of DecP-11. Additionally, we tested the effects of changing PE by PC, which showed a similar trend, this means a significant increase in DCN binding and a limited effect on the binding of DecP-11. However, for vesicles containing PE, when we reduced the content of PS, $K_{p}$ values significantly decreased for DecP-11 and had a limited effect on the binding of DCN. Then, we compared these results with $K_{p}$ values obtained with vesicles

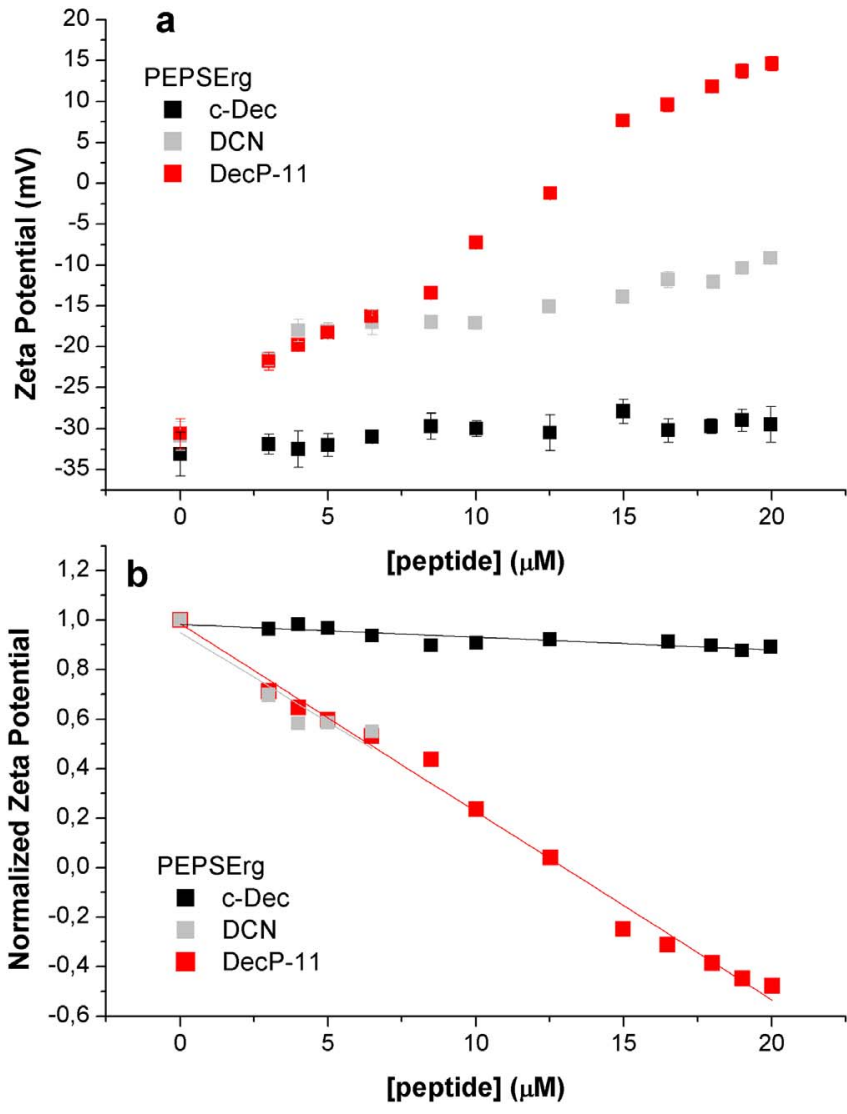

Fig. 3. Zeta potential isotherms and graphical method to determine the partitioning $\left(K_{p}\right)$ of peptides in LUVs, at $25^{\circ} \mathrm{C}$. a) Examples of isotherms of the peptides, for DCN (gray) and DecP-11 (red) at $50 \mu \mathrm{M}$ vesicles concentration and for c-Dec (black) at $33 \mu \mathrm{M}$ LUVs. b) Example of the graphical determination of $K_{p}$.

containing Erg, mimicking the promastigote membranes. This sterol seems to have a limited effect on the peptides' binding. We also evaluated the peptides' binding to vesicles mimicking infected macrophage membranes: $K_{p}$ values for DCN remained at a comparable level with PC/PS 82:18 vesicles (same anionic content), but for DecP-11 a significant decrease was observed. The cyclic peptide, c-Dec, exhibited a poor binding to the vesicles mimicking promastigote and infected macrophages, well correlated to the results obtained in the bio-assays. Fig. 4 summarizes these results. The determined $K_{p}$ values are of the same order already found for other antimicrobial peptides with different lipid bilayers, inclusive by different methods $[37,44]$.

As a general trend, $K_{p}$ values denote more intensive interaction of DecP11 with the different bilayers than DCN, except for PE/PS 72:28 and PE/ PS/Erg 47:28:25, where both peptides bind at equivalent levels. Overall it suggests that besides the electrostatic interactions other physical-chemical features of the zwitterionic phospholipids influence binding.

The changes in the size of vesicles induced by the presence of peptides could indicate aggregation tendencies or a detergent-like mechanism of action. We observed that c-Dec does not induce changes in size of vesicles in any of the compositions of the bilayers tested (data not shown). However, DCN induces significant aggregation on PE/PS 50:50, PE/PS 72:28 and PE/PS/Erg, corresponding to the presence of higher concentration of anionic lipids together with PE. DecP-11 induces the highest aggregation in the presence of these LUVs, although some less intense changes also occur in the remaining environments, except with PC/PS 82:18 vesicles (Fig. 5).

\subsubsection{Lytic activity}

The permeabilization of lipid vesicles is an important feature of the mechanism of action of some peptides, which target the phospholipid 

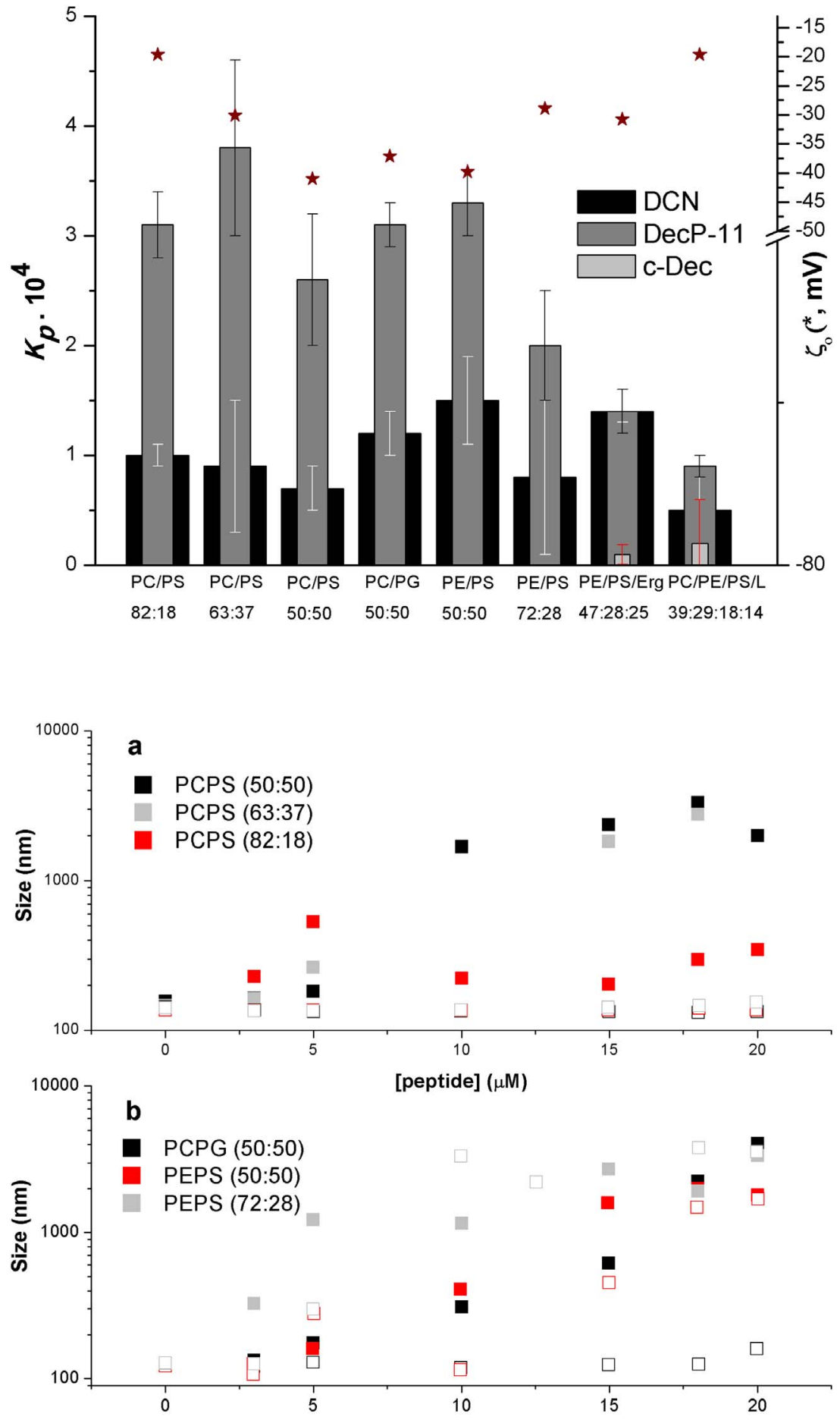

[peptide] $(\mu \mathrm{M})$

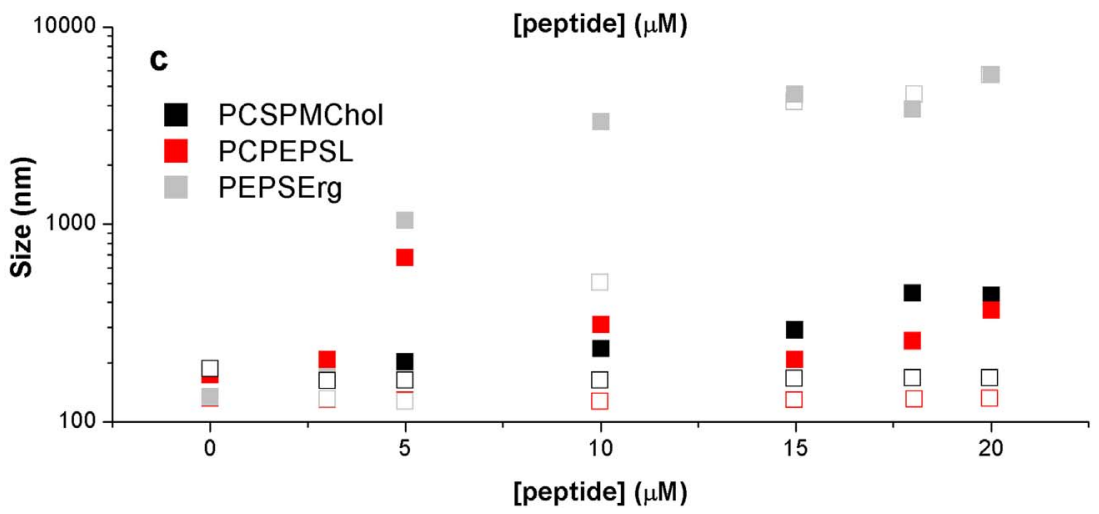

Fig. 4. Calculated partition constants $\left(K_{p}\right)$ for DCN, DecP-11 and cDec values, shown as black, gray and light gray bars, respectively, from zeta potential measurements $\left(\zeta_{0}, \mathrm{mV}\right)$ to vesicles of different lipid compositions, at $\mathrm{pH} 7.5,25^{\circ} \mathrm{C}$. $\left(^{*}\right)$ indicate the zeta potential of vesicles in the absence of peptides (right y-axis).
Fig. 5. Size variations of the different LUVs compositions induced by peptides at $25^{\circ} \mathrm{C}$. a) Effect of PS concentration; b) Effect of PE and PG lipids; c) Zwitterionic and anionic mimetic membranes. DCN, open symbols, DecP-11, closed symbols. Error bars were removed for clarity; they range around $18 \mathrm{~nm}$. 

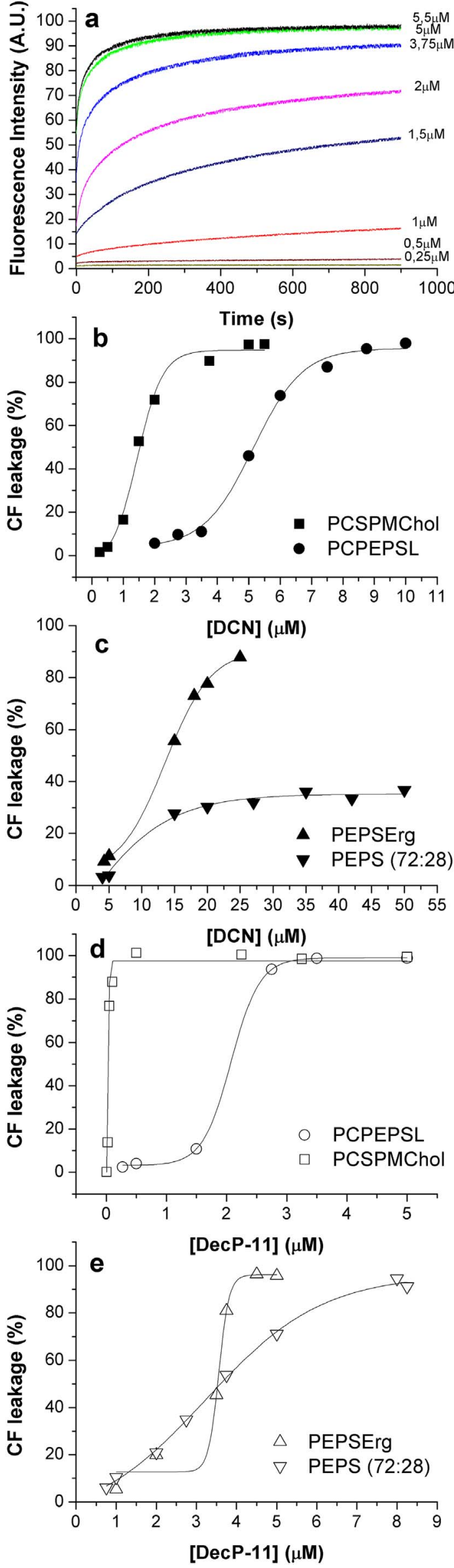

Fig. 6. Lytic activity of peptides observed after 15 min contact with $100 \mu \mathrm{M}$ LUVs, at $25{ }^{\circ} \mathrm{C}$. Dose response curves were fitted according to the sigmoidal Boltzmann model. a) Kinetics of DCN in PCSPMChol, shown as an example. Dose response curves of peptides in PCSPMChol and PCPEPSL. b) DCN and d) DecP-11. Dose response curves of peptides in PEPSErg and PEPS. c) DCN and e) DecP-11.

matrix of the cell membrane and induce pores or defects in these membranes. Fig. 6 demonstrates that DCN and DecP-11 are lytic to PEPSErg, PCPEPSL and PCSPMChol and PEPS, while c-Dec (plots not shown) is not lytic probably due to its poor binding to the same vesicles, as indicated by the zeta potential experiments. DecP-11 presents the most intense lytic activity, reaching almost $100 \% \mathrm{CF}$ leakage with $5 \mu \mathrm{M}$ peptide or less. Some of dose-response curves of this peptide and DCN exhibit a sigmoidal dependence with the concentration of peptides $[\mathrm{P}]$ and a threshold ratio with the lipid concentration $[\mathrm{L}],[\mathrm{P}] /[\mathrm{L}]$, can be inferred. Threshold $[\mathrm{P}] /$ [L] in PEPSErg and PCPEPSL are for DCN 0.063 and 0.029, respectively and for DecP-11 are 0.028 and 0.017 in the same vesicles. In the presence of the zwitterionic PCSPMChol $[\mathrm{P}] /[\mathrm{L}]$ is 0.007 for DCN. The dose response curve for DecP-11 in this zwitterionic vesicle does not show a sigmoidal dependence as well as the dose response curves for both peptides in PEPS 72:28. It is important to mention that the intense lytic activity was already observed below and around $5 \mu \mathrm{M}$ peptide and at this point the aggregation of vesicles was limited.

Comparing DCN and DecP-11, differences are limited to higher DCN concentration required to achieve the same lytic activity. Both peptides do not exhibit a selective behavior (Fig. $6 \mathrm{~b}$ and d). Analyzing the activity of these peptides in promastigotes model systems (Fig. 6c and e), they also show a similar lytic behavior. Since the content of the anionic phospholipid PS is the same in PEPSErg and PEPS 72:28, we could attribute the increased lytic activity in the former model either to the presence of ergosterol or to the lower content of PE. Taking into account the respective $\mathrm{K}_{p}$ values, the latter possibility seems to be more probable.

\subsubsection{Circular dichroism spectroscopy}

CD experiments were performed in 40\% TFE solution, in the presence of SDS micelles and of different LUVs. Figure SI3 shows that in buffer DCN and DecP-11 exhibit different spectra: the spectrum of DCN is compatible with random coil structure while that of DecP-11 shows helical characteristics with stronger absorption around 222 and $208 \mathrm{~nm}$. The remaining different environments, either anionic or zwitterionic, induce structure changes in both peptides, most of them also featuring a helical pattern. In general, DecP-11 displays higher molar ellipticity $\left([\Theta]_{222 n m}\right)$ than DCN, which indicates increased binding revealed in $K_{p}$ determinations. Table 3 summarizes the contributions of several secondary elements to the obtained spectra. The results obtained in TFE solution are in good accordance with the structure profile determined in the NMR experiments, which showed 11 residues in $\alpha$-helix. Although the different LUVs compositions have limited effects on DecP-11 binding, the presence of PC seems to favor intense helical conformations while the presence of $\mathrm{PE}$, in the absence of PC, favor the aggregated forms as indicated in the $\beta$-strand contents (Table 3 ).

Some spectra also exhibit lower mean residue ellipticity values at $222 \mathrm{~nm}$ than at $208 \mathrm{~nm},\left([\Theta]_{222 \mathrm{~nm}}<[\Theta]_{208 \mathrm{~nm}}\right)$, a feature attributed to an aggregation tendency of the peptides in those environments [45]. This tendency was observed for DCN in PEPSErg and for DecP-11 in PCSPMChol. In the presence of PEPSErg and PEPS 72:28 LUVs, DecP-11 exhibit a much noisier and less characteristic spectra than observed in the remaining conditions (Figure SI3, inset). As the deconvolution applied to these spectra indicated a high content of $\beta$-strand, we assumed that intense peptide aggregation is occurring, which agrees with the significant LUVs' size increase (Fig. 5b and c). Comparing these spectra with those previously described for different kinds of $\beta$-strand structures [46], we found that in the presence of PCPSErg LUVs the spectrum resembles that of antiparallel $\beta$-strands, while in PEPS it seems that a mixture of anti-parallel and parallel $\beta$-strands coexist. These are denoted by their more intense absorption bands at approximately $227 \mathrm{~nm}$ and a wider range, from 230 to $210 \mathrm{~nm}$, respectively. 
Table 3

Contributions of the secondary structure elements to the spectra, as calculated from DICHROWEB [47] for DCN and DecP-11 in the different environments.

\begin{tabular}{|c|c|c|c|c|c|c|c|c|}
\hline \multirow[b]{2}{*}{$\%$} & \multicolumn{2}{|c|}{$\alpha$-helix } & \multicolumn{2}{|c|}{$\beta$-strand } & \multicolumn{2}{|l|}{ Turns } & \multicolumn{2}{|c|}{ Random } \\
\hline & DCN & DecP-11 & DCN & DecP-11 & DCN & DecP-11 & DCN & DecP-11 \\
\hline Buffer & 5 & 68 & 36 & 2 & 14 & 10 & 44 & 20 \\
\hline $40 \%$ TFE & 68 & 69 & 5 & 5 & 8 & 9 & 19 & 17 \\
\hline $8 \mathrm{mM}$ SDS & 45 & 75 & 16 & 6 & 10 & 12 & 29 & 7 \\
\hline PCSPMChol $^{\mathrm{a}}$ & 17 & 71 & 29 & 5 & 10 & 11 & 44 & 13 \\
\hline PCPEPSL $^{\mathrm{a}}$ & 57 & 68 & 20 & 11 & 5 & 10 & 18 & 11 \\
\hline PEPSErg ${ }^{\mathrm{a}}$ & 48 & 3 & 19 & 45 & 11 & 18 & 22 & 34 \\
\hline PEPS 72:28 & 38 & 7 & 14 & 38 & 12 & 13 & 36 & 42 \\
\hline
\end{tabular}

${ }^{\mathrm{a}}[\mathrm{LUVs}]=300 \mu \mathrm{M}$;

\section{Discussion}

The unusual features of the amastigote cell surface is on of the obstacles to the development of drug candidates against Leishmania [17]. The pathogen has the ability to develop mechanisms that bypass its host defensive barriers [48], including the acquisition of some of the hosts lipids and the expression of specialized molecules on the cell surface considered determinants of virulence [17]. In this sense the role of membrane in the interaction between the parasite and the host could be seen as a focal point for drug targeting [49].

Insect secretions represent an abundant pond where peptides have evolved with time and can be prospected. Antimicrobial peptides combine features for an interesting antileishmanial drug candidate, as membrane internalization - that would enable direct killing of the amastigote - and low propensity for resistance development [50]. Peptides isolated from different sources as amphibians [11,36], insects [20], and marine organisms [51] have shown antileishmanial activity. These peptides presented potent activity at micromolar concentrations, but often accompanied by hemolytic activity [23,45,52]. Thus, new analogs have been designed by several approaches, including the combination of part of sequences of very active peptides from different species, in an attempt to add functionalities and subtract undesirable effects. This approach seems promising as exemplified by CA(1-8)M (1-18), a hybrid peptide with higher activity on Leishmania than cecropin A without the hemolytic activity of melittin [52], its parental peptides.

In this work we designed peptides based on structural parameters, as obtained from MD simulations, from PH-1, TB and DCN, peptides that showed antileishmanial activity. The alternative, DecP-11, that exhibits structural parameters closer to those of the most active peptide was synthetized and analyzed by NMR. It was further tested for its antileishmanial activity in comparison to DCN and its cyclic version, cDec. The designing of DecP-11 based on MD simulations showed good agreement with the NMR determined structures with RMSD value of $2.17 \AA$ for all atoms.

DCN, c-Dec and DecP-11 were then analyzed for their cytotoxicity against NCTC cells and their antileishmanial activities against $L$. infantum promastigotes and intracellular amastigotes. In relation to miltefosine, DCN and DecP-11 showed, respectively, 4- and 13-fold higher mammalian cytotoxicity and decreased antileishmanial activity, $22 \%$ and $15 \%$ that of the control drug, while the cyclization of DCN totally abolished these activities. Cyclization had been described to improve the biological activity of linear peptides by promoting intramolecular hydrogen bonds and restricting conformations that increase membranolytic activities $[45,53]$. However, the cyclization of the DCN caused a severe loss of its binding capacity to mimetic membranes regardless the lipid composition. Similar effects were found for magainin 2 and melittin, since cyclization significantly reduced their affinity to zwitterionic phospholipid membranes and to a lesser extend to the negatively charged ones [43]. Cyclization reduced the net charge of c-Dec compared to DCN and abolished its amphipathic structure (Figure SI1), probably determining a significant loss of its binding capacity and thus impairing the biological activity. Indeed, amine N-H groups in cyclic peptides are thought to have a special function correlated with the number of intramolecular hydrogen bonding and membrane diffusion rates [53]. However, in the particular case of c-Dec, MD simulations indicated that intramolecular $\mathrm{H}$-bonds are not stable and that the area inside the peptide ring is large enough $\left(7.62 \times 6.24 \AA^{2}\right)$ to accommodate water molecules, which hydrogen bond to the $\mathrm{N}-\mathrm{H}$ and $\mathrm{C}-\mathrm{O}$ groups.

DCN had already been tested for its antileishmanial activity against L. major promastigotes exhibiting $\mathrm{IC}_{50}$ of $11 \mu \mathrm{M}$ and hemolytic activity in human erythrocytes with $\mathrm{EC}_{50}$ of $79 \mu \mathrm{M}$ [20], which is equivalent to the $\mathrm{CC}_{50}$ concentration on NCTC cells presently determined. In many instances, the antileishmanial activity seems to be dependent on the Leishmania species. In our study, the $L$. infantum promastigotes were almost 7 times less susceptible than L. major under effect of DCN [20]. Differential inter-species susceptibility is expected, considering the pathogens high metabolic variance and their abilities to survive in distinct host tissues producing different pathogenicity, particularly cutaneous leishmaniasis to $L$. major or visceral leishmaniasis to $L$. infantum promastigotes [54].

The intracellular influx of Sytox green dye caused by DCN and DecP11 , likewise observed for Temporins (tested against $L$. donovani promastigotes) [24], indicates a typical effect of peptides targeting the membrane $[22,24,36]$. Unexpectedly, DecP-11 showed a more potent permeabilization effect than DCN on promastigotes. This finding suggests different binding, and/or membrane perturbation characteristics, or even the involvement of other events besides those related to the membrane barrier function [1], which lead us to investigate peptidelipid bilayers interactions.

In terms of cationicity, DCN and DecP-11 possess the same charge therefore electrostatic forces guiding the attraction can be ruled out. However, the binding potential of DecP-11 is higher than that of DCN, around 2- to 3-fold, in all kinds of model membranes tested, except in PEPSErg, the promastigote mimetic membrane (Fig. 4), although showing in every case a lower threshold $[\mathrm{P}] /[\mathrm{L}]$ ratio. The calculated mean hydrophobicity of both peptides is comparable, however investigating their respective retention times on RP-HPLC, we found that DecP-11 requires a higher content of hydrophobic solvent to elute, corresponding to a more hydrophobic compound [55]. Generally speaking, differences in the binding potential and lytic activity between DCN and DecP-11 could be attributed to the increased hydrophobic character and longer chain length of the latter peptide. Nevertheless, the faster dye intracellular influx of DecP-11 shown in promastigotes is probably determined by an additional factor, the higher content of aggregated forms. Within experimental error, variation in phospholipid composition and of the anionic character little affects the binding capacity of both peptides. This excludes the possibility of different binding potential and suggests that other contributions beyond the electrostatic interaction are more significant for their biological activity (Fig. 4). 
This is particularly true for electrically neutral membranes where the reduced charge leads to the higher relevance of the hydrophobic interactions [1] as indicated by the high cytotoxicity of DecP-11 toward NCTC line cells and the hemolytic activity of DCN [20]. Also, the trend exhibited in the threshold $[\mathrm{P}] /[\mathrm{L}]$ ratio of the model systems, which show lower values for the less charged LUVs, indicates that the lytic activity is mainly influenced by the hydrophobicity of the peptides. In agreement, DecP-11 showed the most intense lytic activity on zwitterionic LUVs, mimicking erythrocytes, well correlated with its higher cytotoxicity toward NCTC cells, while DCN showed a lower cytotoxicity and lower lytic activity. Peptides able to lyse red blood cells are those presenting high helicity and high permeabilizing efficiency on zwitterionic membranes [1]. Higher helicity and higher hemolytic activity are characteristics found for bombinin $\mathrm{H} 4$ in relation to bombinin $\mathrm{H} 2$ [23].

DecP-11 was generated from PH1, TB and DCN, from which just DCN exhibits some hemolytic activity [20], while the others are nonhemolytic $[56,57]$. PH1 has positively charged residues at positions 7 , 17 and 18, TB at position 10 and DecP-11, following DCN, at positions 7 and 8 . The four peptides are amidated at the C-terminal meaning that they all have another positive charge at the N-terminal (Table 1). Thus, PH1 and TB have well distributed charges, while DCN and DecP-11 do not. Additionally, we observed that their CD spectra in water are predominantly characteristic of random coil conformation (data not shown), but while DCN maintains this conformation in buffer, DecP-11 exhibits a markedly helical pattern (Figure SI3). As thermodynamic studies showed that helix formation involves a significant portion of the interaction energy of magainin 2 with lipid bilayers [43], we checked if this structural feature of DecP-11 would be responsible for the intense lytic activity on the zwitterionic vesicles, by repeating the experiment in the presence of enough urea solution to avoid the pre-formed helical structure. We found that the lytic activity is not influenced by the peptide starting the interaction either at a random coil or at a helical conformation (Figure SI4). These structurally related observations suggest that the charged residues of DecP-11, concentrated in the middle of the chain and easily screened by the saline buffer, facilitate stronger hydrophobic interactions with the acyl chains of phospholipids. While this feature increases the lytic activity on zwitterionic LUVs and the hemolysis, it also might prevent the peptide to reach intracellular targets as would be the case with amastigotes inside macrophages [58].

Peptides strongly bound to the bilayer might require much higher concentrations to kill parasites and these concentrations would be cytotoxic to mammalian cells, abolishing selectivity. Neither DecP-11 nor DCN showed selectivity toward the $L$. infantum forms relative to mammalian cells. Actually DCN was as active toward promastigotes as toward NCTC cells and DecP-11 was much more active toward NCTC cells (Table 2). Important differences between the membrane lipid composition of amastigotes and promastigotes as lower content of metalloproteinase Gp63 and strongly reduced anionic lipophosphoglycan coat $[17,59]$ prompt the idea that amastigotes would be more peptide-sensitive than promastigotes. In practice, Leishmania amastigotes have proven more resistant than promastigotes to several peptides [22,59]. In this concern, it must be kept in mind that amastigotes have a lower cationic character and are localized inside an acid parasitophorous vacuole. Therefore, besides the decreased electrostatic attraction, the peptide has to cross another membrane and be competent in a highly acid environment [60].

Considering the mimetic systems of promastigotes and infected macrophages, DCN and DecP-11 strongly bind and are lytic to them (Fig. 4 and 6), exhibiting more intense permeabilization in the latter model. Binding is less pronounced in the more complex models than in the simpler two-components LUVs, but both peptides are less lytic on PEPS 72:28. In the presence of these LUVs the dose-response curves do not exhibit sigmoidal dependence, suggesting differences in their mechanisms of lysis, which possibly reflect the aggregation process indicated in the DLS and CD experiments.

The $\alpha$-helix conformation of bioactive peptides, a secondary structure acquired by their interaction with membranes, has been correlated with biological activity $[1,2]$. CD experiments determined that the $\alpha$ helix was the main pattern adopted, except for DecP-11 in the presence of Leishmania promastigote mimetic membranes and the simpler model PEPS 72:28. DCN and DecP-11, respectively with 11 and 14 residues in the chain and exhibiting no signs of kinks in the MD and NMR experiments, probably do not form intramolecular $\beta$-strands. Thus, we assume that the spectra deconvolution indicating these structures are probably the result of intermolecular interactions favored by some LUVs compositions, especially those containing PE and PS. Light scattering experiments also show that DCN induces aggregation on PE/PS 50:50, PE/PS 72:28 and PE/PS/Erg, corresponding to the presence of higher concentration of anionic lipids together with PE. DecP-11 induces the highest aggregation in the presence of these LUVs (Fig. 5) and presents the highest $\beta$-strand content (Table 3). Despite the intense binding to promastigote mimetic membranes, the high content of $\beta$ strand structures in DecP-11 was probably crucial for its lower antileishmanial activity in relation to DCN, which shows much lower $\beta$ strand content (Table 3). In analogous peptides, whose structural differences modulate aggregation in the presence of membranes, the increased activity parallels their disassembly, as found for bombinins H2/ H4 against Leishmania [22] and for dermaseptins against bacteria [61]. Peptides aggregated in $\beta$-strands may be impaired in their disturbing activity on membranes, or delayed to reach other targets in the Leishmania cells and thus exhibiting lower activity, as was the case in Gramnegative bacteria for oligomerized mellitin [43].

$\mathrm{PE}$ is one of the major phospholipids in mammalian membranes that turn exposed in the outer leaflet of bilayers, together with PS, when cells are compromised [12,13]. And these lipids are abundant on promastigote, infected macrophages and amastigote membranes. DecP-11 shows strong binding affinity, regardless of the lipid composition of the model systems, and we showed that this does not simply depend on the electrostatic component involved, rather the presence of the aminophospholipids, PE and PS, exerts a specific role [14], inducing aggregation that negatively influenced the antileishmanial activity of the peptide at lower concentration.

\section{Conclusion}

In the present work, we validated by NMR the designed structure of DecP-11, an analog of DCN. DecP-11 exhibits antileishmanial activity toward L. infantum promastigotes and lacks selectivity toward mammalian cells. DecP-11 strongly partitions in anionic vesicles of different compositions and charge density at equivalent levels indicating that hydrophobic interactions prevail. It is lytic to promastigotes and to anionic and zwitterionic phospholipid vesicles. However, the shorter chain DCN, with similar partition coefficients and less intense lytic activity, shows lower IC $_{50}$ value for promastigotes. This apparent contradiction could be explained considering the differences induced by the presence of the aminophospholipids PE and PS, in the absence of PC, in the secondary structure of DCN and DecP-11 and the observed aggregation behavior of DecP-11. In the environment mimicking the promastigote membrane, the helical DecP-11 assumes mostly $\beta$-strand structures and induces strong size increase of these vesicles. Peptides aggregated in $\beta$-strands may be impaired in their disturbing activity on membranes, or delayed to reach other targets in the Leishmania cells and thus exhibiting lower activity. Thus, the design of new antileishmanial peptides should attempt to avoid sequences that are prone to assume aggregated forms in the presence of aminophospholipids.

\section{Author contributions}

D.B.M., M.R.V., V.F., V.A.C.S., M.E.R.G and M.L.L performed the experiments. D.B.M., V.F., M.E.R.G, M.L.L. and A.G.T. analyzed the 
data and interpreted the results. M.P.S.C designed the study. V.F., M.L.L., A.G.T. and M.P.S.C wrote the manuscript. All authors reviewed and discussed the results.

\section{Funding}

This study was supported by research grants from Fundação de Amparo à Pesquisa do Estado de São Paulo (FAPESP 2012/24259-0 and 2014/08372-7 to M.P.S.C; 2014/11877-3 to M.R.V.; 2015/17331-5 to V.A.C.S.; and 2013/50228-8 to AGT).

\section{Transparency document}

The Transparency document associated with this article can be found, in online version.

\section{Acknowledgements}

D.B.M, M.L.L and M.E.R.G. are PhD fellowship recipients from CAPES and CNPq. The authors acknowledge The Brazilian Biosciences National Laboratory (LNBio) for the NMR time under proposal RMN 18763, Prof. Dr. Joao Ruggiero Neto for the use of the CD spectropolarimeter and Prof. Mauricio Boscolo for the use of the spectrofluorometer.

\section{Appendix A. Supplementary data}

Supplementary data to this article can be found online at http://dx. doi.org/10.1016/j.bbagen.2017.08.003.

\section{References}

[1] M. Dathe, T. Wieprecht, Structural features of helical antimicrobial peptides: their potential to modulate activity on model membranes and biological cells, Biochim. Biophys. Acta 1462 (1999) 71-87.

[2] N. Papo, Y. Shai, Can we predict biological activity of antimicrobial peptides from their interactions with model phospholipid membranes? Peptides 24 (2003) 1693-1703.

[3] M.R. Yeaman, N.Y. Yount, Mechanisms of antimicrobial peptide action and resistance, Pharmacol. Rev. 55 (2003) 27-55.

[4] M. Zasloff, Antimicrobial peptides of multicellular organisms, Nature 415 (2002) 389-395.

[5] M. Torrent, D. Pulido, L. Rivas, D. Andreu, Antimicrobial peptide action on parasites, Curr. Drug Targets 13 (2012) 1138-1147.

[6] A.K. Marr, B.S. McGwire, W.R. McMaster, Modes of action of leishmanicidal antimicrobial peptides, Future Microbiol 7 (2012) 1047-1059.

[7] S.L. Cobb, P.W. Denny, Antimicrobial peptides for leishmaniasis, Curr. Opin. Investig. Drugs 11 (2010) 868-875.

[8] Z. Raja, S. André, C. Piesse, D. Sereno, P. Nicolas, T. Foulon, B. Oury, A. Ladram, Structure, antimicrobial activities and mode of interaction with membranes of bovel phylloseptins from the painted-belly leaf frog, Phyllomedusa sauvagii, PLoS One 8 (2013) e70782, , http://dx.doi.org/10.1371/journal.pone.0070782.

[9] M. Simmaco, G. Kreil, D. Barra, Bombinins, antimicrobial peptides from Bombina species, Biochim. Biophys. Acta 1788 (2009) 1551-1555.

[10] L. Rivas, J.R. Luque-Ortega, D. Andreu, Amphibian antimicrobial peptides and Protozoa: lessons from parasites, Biochim. Biophys. Acta 1788 (2009) 1570-1581.

[11] S.A. Kückelhaus, J.R. Leite, M.I. Muniz-Junqueira, R.N. Sampaio, C. Bloch, C.E. Tosta, Antiplasmodial and antileishmanial activities of phylloseptin-1, an antimicrobial peptide from the skin secretion of Phyllomedusa azurea (Amphibia), Exp. Parasitol. 123 (2009) 11-16.

[12] M.C. Larson, J.E. Woodliff, C.A. Hillery, T.J. Kearl, M. Zhao, Phosphatidylethanolamine is externalized at the surface of microparticles, Biochim. Biophys. Acta 1821 (2012) 1501-1507.

[13] D.A. Phoenix, F. Harris, M. Mura, S.R. Dennison, The increasing role of phosphatidylethanolamine as a lipid receptor in the action of host defense peptides, Prog. Lipid Res. 59 (2015) 26-37.

[14] R.M. Epand, C. Walker, R.F. Epand, N.A. Magarvey, Molecular mechanisms of membrane targeting antibiotics, Biochim. Biophys. Acta 2016 (1858) 980-987.

[15] K. Zhang, S.M. Beverley, Phospholipid and sphingolipid metabolism in Leishmania, Mol. Biochem. Parasitol. 170 (2010) 55-64.

[16] K.S. Fernandes, P.E. Narcizo de Souza, M.L. Dorta, A. Alonso, The cytotoxic activity of miltefosine against Leishmania and macrophages is associated with dynamic changes in plasma membrane proteins, Biochim. Biophys. Acta 1859 (2017) 1-9.

[17] T. Naderer, J.E. Vince, M.J. McConville, Surface determinants of Leishmania parasites and their role in infectivity in the mammalian host, Curr. Mol. Med. 4 (2004) $649-665$.
[18] C. Henriques, G.C. Atella, V.L. Bonilha, W. de Souza, Biochemical analysis of proteins and lipids found in parasitophorous vacuoles containing Leishmania amazonensis, Parasitol. Res. 89 (2003) 123-133.

[19] A. Mor, Multifunctional host defense peptides: antiparasitic activities, FEBS J. 276 (2009) 6474-6482, http://dx.doi.org/10.1111/j.1742-4658.2009.07358.x.

[20] K. Konno, M. Rangel, J.S. Oliveira, M.P. Dos Santos Cabrera, R. Fontana, I.Y. Hirata I. Hide, Y. Nakata, K. Mori, M. Kawano, H. Fuchino, S. Sekita, J. Ruggiero Neto, Decoralin, a novel linear cationic alpha-helical peptide from the venom of the solitary eumenine wasp Oreumenes decoratus, Peptides 28 (2007) 2320-2327.

[21] M. Rangel, M.P. Dos Santos Cabrera, K. Kazuma, K. Ando, X. Wang, M. Kato, K. Nihei, I.Y. Hirata, T.J. Cross, A.N. Garcia, E.L. Faquim-Mauro, M.R. Franzolin, H. Fuchino, K. Mori-Yasumoto, S. Sekita, M. Kadowaki, M. Satake, K. Konno, Chemical and biological characterization of four new linear cationic $\alpha$-helical peptides from the venoms of two solitary eumenine wasps, Toxicon 57 (2011) 1081-1092.

[22] M.L. Mangoni, N. Papo, J.M. Saugar, D. Barra, Y. Shai, M. Simmaco, L. Rivas, Effect of natural L- to D-amino acid conversion on the organization, membrane binding, and biological function of the antimicrobial peptides bombinins $\mathrm{H}$, Biochemistry 45 (2006) 4266-4276.

[23] M.L. Mangoni, D. Fiocco, D. Barra, M. Simmaco, Bombinins in Handbook of Biologically Active Peptides, (2006), pp. 333-337 (chapter 50).

[24] M.L. Mangoni, J.M. Saugar, M. Dellisanti, D. Barra, M. Simmaco, L. Rivas, Temporins, small antimicrobial peptides with leishmanicidal activity, J. Biol. Chem. 280 (2005) 984-990.

[25] M.L. Mangoni, Temporins, anti-infective peptides with expanding properties, Cell. Mol. Life Sci. 63 (2006) 1060-1069.

[26] M.D. Diaz, M. Fioroni, K. Burger, S. Berger, Evidence of complete hydrophobic coating of bombesin by trifluoroethanol in aqueous solution: an NMR spectroscopic and molecular dynamics study, Chem. Eur. J. 8 (2002) 1663-1669.

[27] M.K. Wassef, T.B. Fioretti, D.M. Dwyer, Lipid analyses of isolated surface membranes of Leishmania donovani promastigotes, Lipids 20 (1985) 108-115.

[28] K. Lohner, E.J. Prenner, Differential scanning calorimetry and X-ray diffraction studies of the specificity of the interaction of antimicrobial peptides with membrane-mimetic systems, Biochim. Biophys. Acta 1462 (1999) 141-156.

[29] M.V. Lizenko, T.I. Regerand, A.M. Bakhirev, E.I. Lizenko, Lipid composition of cells and low-density lipoproteins in blood serum of human and some vertebrate species, J. Evol. Biochem. Physiol. 47 (2011) 428-437.

[30] D. Eisenberg, E. Schwarz, M. Komaromy, R. Wall, Analysis of membrane and surface protein sequences with the hydrophobic moment plot, J. Mol. Biol. 179 (1984) $125-142$.

[31] H.S. Won, M.D. Seo, S.L. Jung, S.J. Lee, S.J. Kang, W.S. Son, H.J. Kim, T.K. Park, S.J. Park, B.J. Lee, Structural determinants for the membrane interaction of novel bioactive undecapeptides derived from gaegurin 5, J. Med. Chem. 49 (2006) 4886-4895.

[32] M.E.R. Guerra, V. Fadel, V.G. Maltarollo, G. Baldissera, K.M. Honorio, J.R. Ruggiero, M.P. Dos Santos Cabrera, MD simulations and multivariate studies for modeling the antileishmanial activity of peptides, Chem. Biol. Drug Des. (2017), http://dx.doi.org/10.1111/cbdd.12970.

[33] J.Q. Reimão, F.A. Colombo, V.L. Pereira-Chioccola, A.G. Tempone, Effectiveness of liposomal buparvaquone in an experimental hamster model of Leishmania (L.) infantum chagasi, Exp. Parasitol. 130 (2012) 195-199.

[34] E.G. Pinto, D.C. Pimenta, M.M. Antoniazzi, C. Jared, A.G. Tempone, Antimicrobial peptides isolated from Phyllomedusa nordestina (Amphibia) alter the permeability of plasma membrane of Leishmania and Trypanosoma cruzi, Exp. Parasitol. 135 (2013) 655-660.

[35] M.P. Dos Santos Cabrera, G. Baldissera, L.C. Silva-Gonçalves, B.M. de Souza, K.A. Riske, M.S. Palma, J.R. Ruggiero, M. Arcisio-Miranda, Combining experimental evidence and molecular dynamic simulations to understand the mechanism of action of the antimicrobial octapeptide Jelleine-I, Biochemistry 53 (2014) 4857-4868 http://dx.doi.org/10.1021/bi5003585.

[36] J.M. Freire, M.M. Domingues, J. Matos, M.N. Melo, A.S. Veiga, N.C. Santos, M.A.R.B. Castanho, Using zeta-potential measurements to quantify peptide partition to lipid membranes, Eur. Biophys. J. 40 (2011) 481-487, http://dx.doi.org/10. 1007/s00249-010-0661-4.

[37] N.C. Santos, M. Prieto, M.A.R.B. Castanho, Quantifying molecular partition into model systems of biomembranes: an emphasis on optical spectroscopic methods, Biochim. Biophys. Acta 1612 (2003) 123-135.

[38] F.G.S. Delaglio, NMRPipe: a multidimensional spectral processing system based on UNIX pipes, J. Biomol. NMR 6 (1995) 277-293.

[39] R. Keller, The computer aided resonance assignment tutorial, CARA Website, CANTINA Verlag, Goldau, 2004(Available: http://cara.nmr-software.org/portal/ ).

[40] T. Herrmann, UNIO10-Automated NMR analysis for protein structure determination and more, Available at http://www.unio-nmr.eu, (2002).

[41] T.G.P. Herrmann, Protein NMR structure determination with automated NOE assignment using the new software CANDID and the torsion angle dynamics algorithm DYANA, J. Mol. Biol. 319 (2002) 209-227.

[42] A.T. Brünger, P.D. Adams, G.M. Clore, W.L. DeLano, P. Gros, R.W. GrosseKunstleve, J.S. Jiang, J. Kuszewski, M. Nilges, N.S. Pannu, R.J. Read, L.M. Rice, T. Simonson, G.L. Warren, Crystallography \& NMR system: a new software suite for macromolecular structure determination, Acta Crystallogr. D Biol. Crystallogr. 54 (1998) 905-921.

[43] T. Unger, Z. Oren, Y. Shai, The effect of cyclization of magainin 2 and melittin analogues on structure, function, and model membrane interactions: implication to their mode of action, Biochemistry 40 (2001) 6388-6397.

[44] M.P. Dos Santos Cabrera, M. Arcisio-Miranda, R. Gorjão, N.B. Leite, B.M. de Souza, R. Curi, J. Procopio, J. Ruggiero Neto, M.S. Palma, Influence of the bilayer 
composition on the binding and membrane disrupting effect of Polybia-MP1, an antimicrobial mastoparan peptide with leukemic T-lymphocyte cell selectivity, Biochemistry 51 (2012) 4898-4908 http://dx.doi.org/10.1021/bi201608d.

[45] S.E. Blondelle, B. Forood, R.A. Houghten, E. Perez-Payá, Secondary structure induction in aqueous vs membrane-like environments, Biopolymers 42 (1997) 489-498.

[46] A. Micsonaia, F. Wien, L. Kernya, Y. Lee, Y. Goto, M. Réfrégiers, J. Kardos, Accurate secondary structure prediction and fold recognition for circular dichroism spectroscopy. PNAS, (2015), pp. E3095-E3103, http://dx.doi.org/10.1073/pnas. 1500851112.

[47] L. Whitmore, B.A. Wallace, DICHROWEB, an online server for protein secondary structure analyses from circular dichroism spectroscopic data, Nucleic Acids Res. 32 (2004) 668-673.

[48] S.J. Turco, A. Descoteaux, The lipophosphoglycan of Leishmania parasites, Annu. Rev. Microbiol. 46 (1992) 65-94.

[49] R. Zufferey, S. Allen, T. Barron, D.R. Sullivan, P.W. Denny, I.C. Almeida, D.F. Smith, S.J. Turco, M.A. Ferguson, S.M. Beverley, Ether phospholipids and glycosylinositolphospholipids are not required for amastigote virulence or for inhibition of macrophage activation by Leishmania major, J. Biol. Chem. 278 (2003) $44708-44718$

[50] A.K. Marr, S. Cen, R.E.W. Hancock, W.R. McMaster, Identification of synthetic and natural host defense peptides with leishmanicidal activity, Antimicrob. Agents Chemother. 60 (2016) 2484-2491, http://dx.doi.org/10.1128/AAC.02328-15.

[51] J.R. Luque-Ortega, L.J. Cruz, F. Albericio, L. Rivas, The antitumoral depsipeptide IB-01212 kills Leishmania through an apoptosis-like process involving intracellular targets, Mol. Pharm. 7 (2010) 1608-1617.

[52] D. Andreu, J. Ubach, A. Boman, B. Wåhlin, D. Wade, R.B. Merrifield, H.G. Boman, Shortened cecropin A-melittin hybrids. Significant size reduction retains potent antibiotic activity, FEBS Lett. 296 (1992) 190-194.

[53] T. Rezai, B. Yu, G.L. Millhauser, M.P. Jacobson, R.S. Lokey, Testing the conformational hypothesis of passive membrane permeability using synthetic cyclic peptide diastereomers, J. Am. Chem. Soc. 128 (2006) 2510-2511.

[54] G.D. Westrop, R.A. Williams, L. Wang, T. Zhang, D.G. Watson, A.M. Silva, G.H. Coombs, Metabolomic analyses of Leishmania reveal multiple species differences and large differences in amino acid metabolism, PLoS One 10 (2015) e0136891.

[55] T. Tachi, R.F. Epand, R.M. Epand, K. Matsuzaki, Position-dependent hydrophobicity of the antimicrobial magainin peptide affects the mode of peptide-lipid interactions and selective toxicity, Biochemistry 41 (2002) 10723-10731.

[56] J.R.S.A. Leite, L.P. Silva, M.I.S. Rodrigues, M.V. Prates, G.D. Brand, B.M. Lacava, R.B. Azevedo, A.L. Bocca, S. Albuquerque, C. Bloch Jr., Phylloseptins: a novel class of anti-bacterial and anti-protozoan peptides from the Phyllomedusa genus, Peptides 26 (2005) 565-573.

[57] M. Simmaco, G. Mignogna, S. Canofeni, R. Miele, M.L. Mangoni, D. Barra, D. Temporins, Antimicrobial peptides from the European red frog Rana temporaria, Eur. J. Biochem. 242 (1996) 788-792.

[58] J.K. Ghosh, D. Shaool, P. Guillaud, L. Ciceron, D. Mazier, I. Kustanovich, Y. Shai, A. Mor, Selective cytotoxicity of dermaseptin S3 toward intraerythrocytic Plasmodium falciparum and the underlying molecular basis, J. Biol. Chem. 272 (1997) 31609-31616.

[59] G. Eggimann, K. Sweeney, H.L. Bolt, N. Rozatian, S.L. Cobb, P.W. Denny, The role of lipophosphoglycan in the resistance of Leishmania mexicana to the temporin family of anti-microbial peptides, Molecules 20 (2015) 2775-2785.

[60] M. Vermeersch, R.I. da Luz, K. Toté, J.P. Timmermans, P. Cos, L. Maes, In vitro susceptibilities of Leishmania donovani promastigote and amastigote stages to antileishmanial reference drugs: practical relevance of stage-specific differences, Antimicrob. Agents Chemother. 53 (2009) 3855-3859.

[61] L. Gaidukov, A. Fish, A. Mor, Analysis of membrane-binding properties of dermaseptin analogues: relationships between binding and cytotoxicity, Biochemistry 42 (2003) 12866-12874. 